\title{
Open Versus Transanal Pull-Through for Hirschsprung Disease: A Systematic Review of Long-Term Outcome
}

\author{
Jan-Hendrik Gosemann ${ }^{1} \quad$ Florian Friedmacher ${ }^{2}$ Benno Ure ${ }^{1}$ Martin Lacher $^{1}$ \\ ${ }^{1}$ Department of Pediatric Surgery, Hannover Medical School, \\ Hannover, Germany \\ 2 National Children's Research Centre, Our Lady's Children's Hospital, \\ Address for correspondence Jan-Hendrik Gosemann, Department of \\ Pediatric Surgery, Hannover Medical School, Carl-Neuberg-Str. 1, \\ Crumlin, Dublin, Ireland \\ Hannover 30625, Germany (e-mail: Gosemann.Jan@mh-hannover.de).
}

Eur J Pediatr Surg 2013;23:94-102.

\begin{abstract}
Keywords

- Hirschsprung

- pull-through

- outcome

- open surgery

- transanal surgery

Introduction Various surgical techniques for the treatment of Hirschsprung disease (HD) have been proposed. The most relevant long-term complications of HD surgery include constipation, soiling/incontinence, enterocolitis, and anastomotic stricture. To date, there has been no randomized controlled trial evaluating the long-term outcome of OPEN surgery compared with transanal approaches with and without laparoscopy (laparoscopic-assisted transanal-endorectal pull-through [L-TERPT] and transanal-endorectal pull-through [TERPT]). We performed a systematic literature review of the longterm outcome of OPEN surgery compared with L-TERPT/TERPT.

Methods Our systematic review of the recent literature (2008 to 2012) included reports on long-term outcome of either OPEN surgery or L-TERPT/TERPT with a minimum follow-up period of 12 months. With the cumulative data, a comparative meta-analysis was performed for the outcome parameters "constipation," "soiling/ incontinence," "enterocolitis," and "anastomotic stricture."

Results Functional outcome of surgical techniques for HD was highly variable. We could show a significant advantage of L-TERPT/TERPT over OPEN surgery regarding the incidence of soiling/incontinence and constipation. No differences were seen for enterocolitis and anastomotic stricture.

Conclusion Significant differences in the long-term outcome of OPEN surgery compared with L-TERPT/TERPT were identified in this review. We conclude from our data that L-TERPT/TERPT represents a valid option in the treatment of HD and might have some advantages over the OPEN techniques. However, the present data should be interpreted carefully due to limitations in the quality of the study design in most reports. Prospective, randomized, multicenter trials are urgently needed to overcome this weakness of the current literature.
\end{abstract}

\section{Introduction}

Various surgical procedures for the treatment of Hirschsprung disease (HD) have been proposed. The principle of

received

March 12, 2013

accepted

March 12, 2013

published online

April 9, 2013 all techniques is the resection of the aganglionic segment and anastomosis. In 1948, Swenson and Bill first described a staged repair for neonates and infants with HD: preliminary

(c) 2013 Georg Thieme Verlag KG Stuttgart · New York
DOI http://dx.doi.org/ 10.1055/s-0033-1343085. ISSN 0939-7248. 
colostomy followed by a pull-through operation via laparotomy. ${ }^{1}$ In the early 1980s, a better understanding of disease pathogenesis with earlier diagnosis together with technical refinements allowed surgeons to perform single-stage pullthroughs. $^{2}$

The next milestone was reached in the 1990s, when Georgeson et al minimized the invasiveness of the procedure by performing a transanal mucosectomy combined with a laparoscopic bowel resection. ${ }^{3}$ In addition to all the benefits of a minimally invasive technique, the advantage of this operation was the possibility to obtain intraoperative seromuscular biopsies to determine the extension of aganglionosis before starting endorectal dissection and mesenteric division. The introduction of a single-stage transanal endorectal pullthrough (TERPT) by de la Torre-Mondragon and Ortega in $1998^{4}$ drastically changed the treatment of HD. This operation was performed entirely via the anus and did not require a laparotomy or laparoscopy, therefore potentially minimizing the risk of intraperitoneal contamination, adhesion formation, and damaging the pelvic structures. As it offered not only the safety and efficacy of the previous techniques but also all the advantages of a minimally invasive technique such as better pain control, faster discharge from hospital, and a better cosmetic result, this technique became the most popular approach for the treatment of HD in many institutions. ${ }^{5-8}$

In the last decade, it has been well documented that TERPT is a safe and efficient operation with early complication rates comparable to laparoscopic or open procedures. ${ }^{7,9,10}$ However, the possible consequences of transanal mobilization of rectum and colon by stretching the anal sphincters have caused considerable concern about long-term anorectal function, particularly soiling, constipation, and incontinence. ${ }^{10-14}$

Therefore, the aim of this study was to review the available data on long-term functional results in HD patients operated with conventional transabdominal pull-through (OPEN) compared with transanal approaches with and without laparoscopy (laparoscopic-assisted transanal-endorectal pullthrough [L-TERPT] and transanal-endorectal pull-through [TERPT]) reported in the recent literature.

\section{Methods}

A systematic PubMed search was performed to identify publications on outcome of children with HD, who underwent either OPEN, L-TERPT, or TERPT. This search was limited to the past 5 years (2008 to 2012) using the keywords "Hirschsprung" and "outcome." Reference lists were screened for additional studies.

Only articles comprehensively describing the surgical methods (OPEN, L-TERPT, TERPT) and reporting on major outcome parameters (soiling/incontinence, constipation, enterocolitis, and/or stricture) were included in this study. Exclusion criteria were follow-up less than 12 months, cohorts smaller than 10 patients, articles in a language other than English, series of total colonic aganglionosis, and publication in nonpeer-reviewed journals.

Data extracted from included articles were study characteristics (authors, journal, publication year, sample size, surgical technique, and follow-up period) and patient characteristics (age at surgery, extent of aganglionosis). Specific information on the outcome parameters constipation, enterocolitis, stricture, incontinence, and soiling were collected and analyzed.

Since not all outcome parameters were reported in all articles, each specific parameter was analyzed according to the number of patients in whom that item was assessed. This enabled the calculation of the incidence of each specific outcome parameter. With these data, a cumulative metaanalysis was performed to compare long-term outcome of patients who underwent OPEN surgery with patients who underwent L-TERPT/TERPT surgery. The latter groups were analyzed as one group due to the transanal approach in both. Odds ratio (OR) with 95\% confidence interval (CI) were calculated. Statistical differences were considered as significant for a $p$ value $<0.05$ (two-tailed).

\section{Results}

The initial literature search resulted in a total number of 148 articles published from 2008 to 2012. Of these, 130 articles were excluded because they did not fulfill the inclusion criteria (-Fig. 1). Eighteen articles finally met the inclusion criteria and were analyzed in detail. ${ }^{10,14-30}$

\section{Study Population Characteristics}

A total of 1,412 subjects with HD were included in this review (range: 10 to 192 patients per study). Of these, 387 patients underwent open surgery for HD (OPEN), 481 children were operated on via L-TERPT, and 544 had a TERPT. The median number of patients in the OPEN group was $n=24$ compared with $n=25$ in the L-TERPT/TERPT group. Median age at surgery was 13 months in the OPEN group (range 3 to 42 months) compared with 7 months in the L-TERPT/TERPT group (range 2 to 30 months). Statistical analysis of group sizes and age at surgery revealed no significant difference ( $p>0.05$ ). Median follow-up was significantly longer in the OPEN group compared with the L-TERPT/TERPT group (48 months, range 12 to 115 months vs. 36 months, range 12 to 80 months; $p<0.05$ ).

\section{Constipation}

The mean rate of constipation was $21 \%$ (range 0 to $59 \%$ ) in the OPEN group compared with $10 \%$ (range 0 to $27 \%$ ) in the LTERPT/TERPT group. A cumulative meta-analysis revealed that constipation was significantly more frequent after OPEN surgery compared with L-TERPT/TERPT (OR 3.89 [95\% CI, 2.69 to 5.62]; $p<0.0001$ ) ( - Fig. 2, - Table 1).

\section{Soiling/Incontinence}

The mean rate of soiling/incontinence was 33\% (range 10 to $75 \%$ ) in the OPEN group compared with 25\% (range 2 to $88 \%$ ) in the L-TERPT/TERPT group. Soiling/incontinence occurred significantly more frequently after OPEN surgery compared with L-TERPT/TERPT (OR 3.87 [95\% CI, 2.83 to 5.31]; $p<0.0001$ ) (-Fig. 2, - Table 2). 


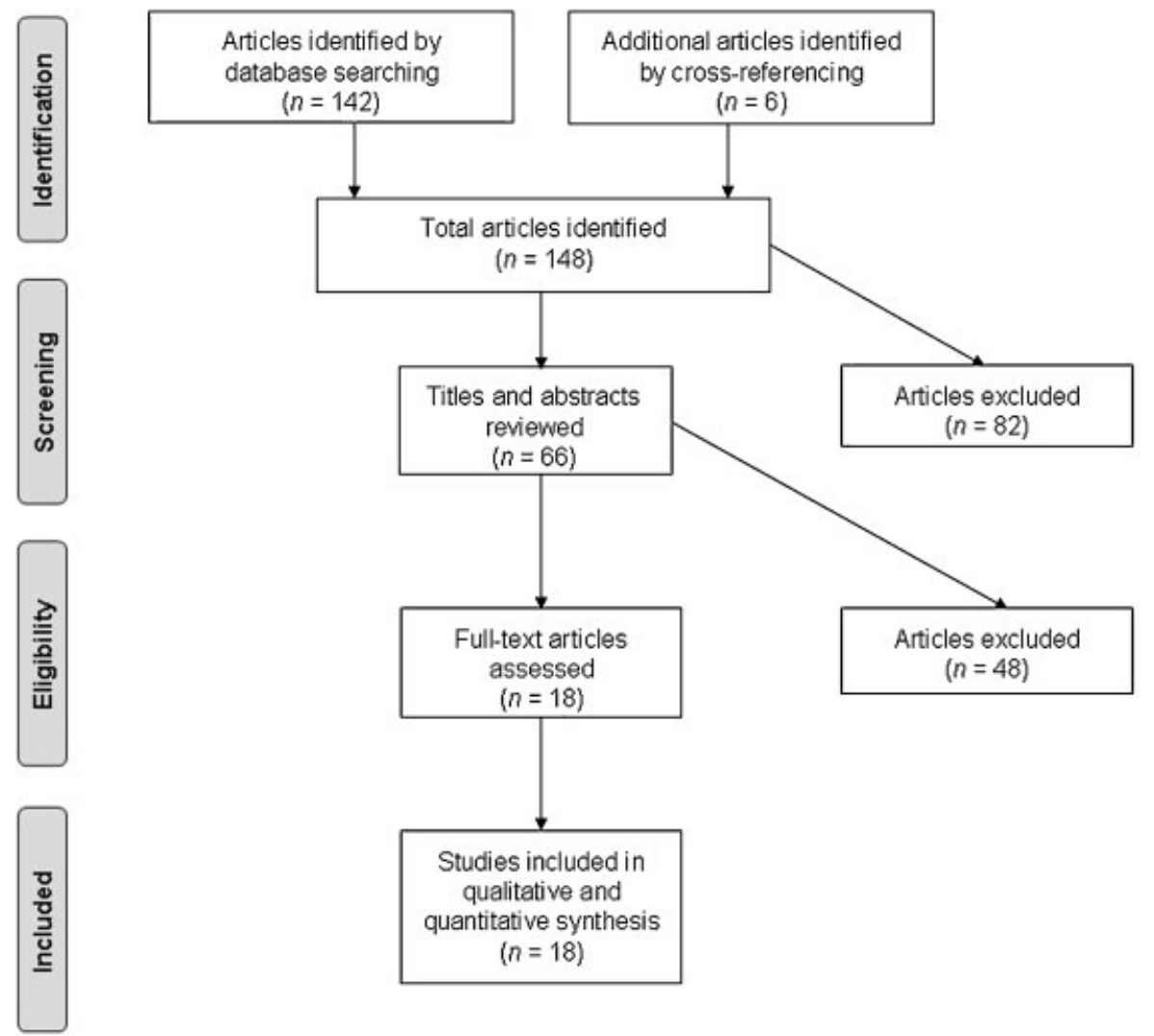

Fig. 1 Flowchart indicating the methodology and stages of this systematic review.

\section{Enterocolitis}

The mean frequency of enterocolitis was $14 \%$ (range 3 to $31 \%$ ) in the OPEN group compared with $14 \%$ (range 0 to $34 \%$ ) in the L-TERPT/TERPT group. There was no significant difference between the rate of enterocolitis after OPEN pull-through and the rate of enterocolitis after L-TERPT/TERPT (OR 1.04 [95\% CI, 0.73 to 1.50 ]; $p=0.8177$ ) ( -Fig. 2 , - Table 3 ).

\section{Anastomotic Stricture}

Seven percent (range 0 to $21 \%$ ) of children in the OPEN group developed an anastomotic stricture compared with 9\% (range

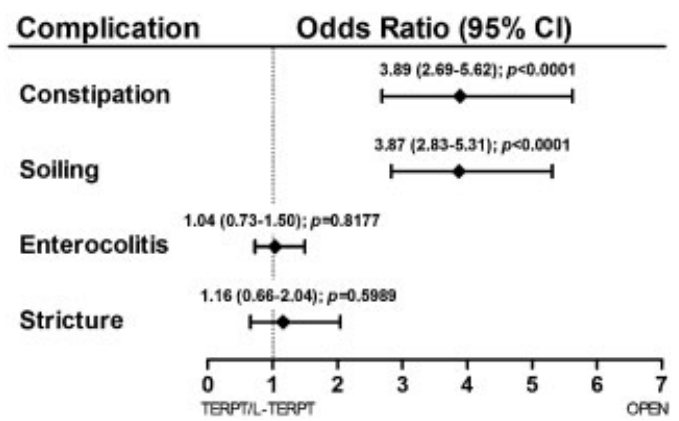

Fig. 2 Odds ratio for the outcome parameters constipation and soiling/incontinence revealed a significant higher rate of constipation and soiling/incontinence in the OPEN group compared with L-TERPT/ TERPT $(p<0.0001,95 \% \mathrm{Cl})$. No difference was found for the incidence of enterocolitis and anastomotic stricture.
0 to $43 \%$ ) in the L-TERPT/TERPT group. No significant difference was found comparing occurrence of strictures after OPEN pull-through versus L-TERPT/TERPT (OR 1.16 [95\% CI, 0.66 to 2.04 ]; $p=0.5989$ ) ( -Fig. 2 , - Table 4).

\section{Discussion}

Several large multicenter series confirmed an excellent safety and feasibility of L-TERPT/TERPT. It was suggested that LTERPT and TERPT had advantages over OPEN procedures such as shorter time to feeding, shorter hospital stay, less pain, and better cosmesis. ${ }^{15,31-35}$ Recently, Langer et al discussed that although L-TERPT and TERPT are often thought of as separate approaches, the techniques are similar in most aspects. ${ }^{33}$ The main difference is the preparation of the rectum: Laparoscopy allows additional dissection of the rectum from above, whereas by using a transanal technique, the rectum is dissected from below only. The authors further stated that many "transanal" surgeons used laparoscopy for biopsy and/or mobilization of the proximal colon without using it for rectal dissection, making the "L-TERPT" technique a very heterogeneous approach. Therefore, no study has been published to date comparing L-TERPT with TERPT and Langer conclude that this question has increasingly become less relevant. ${ }^{33}$ Hence, for the present study, we decided to analyze L-TERPT and TERPT as one group.

However, functional results after transanal repair versus open techniques may not be superior and even associated 
Table 1 Frequency of postoperative constipation

\begin{tabular}{|c|c|c|c|c|c|c|}
\hline Group & Author & Year & Surgical technique & Patients, $N$ & Constipation, $N$ & Constipation, \% \\
\hline \multirow[t]{13}{*}{ OPEN } & Ishikawa et al & 2008 & Unspecified & 20 & 0 & 0 \\
\hline & Aslanabadi et al & 2008 & Swenson & 21 & 1 & 5 \\
\hline & Mattioli et al & 2008 & Soave & 21 & 2 & 10 \\
\hline & Gad El-Hak et al & 2010 & Swenson & 52 & 5 & 10 \\
\hline & Yokoi et al & 2009 & Swenson & 64 & 9 & 14 \\
\hline & Stensrud et al & 2010 & Unspecified & 24 & 4 & 17 \\
\hline & Giuliani et al & 2011 & Duhamel & 24 & 4 & 17 \\
\hline & Tannuri et al & 2009 & Duhamel & 29 & 6 & 21 \\
\hline & Romero et al & 2011 & Soave, Duhamel, Swenson, Rehbein & 29 & 8 & 28 \\
\hline & Yokoi et al & 2009 & Modified Swenson & 10 & 3 & 30 \\
\hline & Nah et al & 2012 & Duhamel & 41 & 14 & 34 \\
\hline & Aworanti et al & 2012 & Soave & 35 & 12 & 34 \\
\hline & Gunnarsdottir & 2010 & Duhamel & 17 & 10 & 59 \\
\hline Total & & & & 387 & 78 & 21 \\
\hline \multirow[t]{5}{*}{ L-TERPT } & Giuliani et al & 2011 & Soave & 14 & 0 & 0 \\
\hline & Tang et al & 2012 & Soave & 182 & 3 & 2 \\
\hline & Nguyen et al & 2009 & Soave & 157 & 5 & 3 \\
\hline & Yokoi et al & 2009 & Swenson & 15 & 1 & 7 \\
\hline & Mattioli et al & 2008 & Soave & 25 & 3 & 12 \\
\hline \multirow[t]{9}{*}{ TERPT } & Aslanabadi et al & 2008 & Soave & 21 & 0 & 0 \\
\hline & Yang et al & 2012 & Soave & 137 & 4 & 3 \\
\hline & Dutta & 2010 & Soave & 45 & 5 & 11 \\
\hline & Tannuri et al & 2009 & Soave & 35 & 2 & 6 \\
\hline & Kim et al & 2010 & Soave & 192 & 16 & 8 \\
\hline & Romero et al & 2011 & Unspecified & 24 & 2 & 8 \\
\hline & Aworanti et al & 2012 & Soave & 16 & 4 & 25 \\
\hline & Stensrud et al & 2010 & Soave & 28 & 7 & 25 \\
\hline & Gunnarsdottir & 2010 & Soave & 11 & 3 & 27 \\
\hline Total & & & & 902 & 55 & 10 \\
\hline
\end{tabular}

Abbreviations: $\mathrm{Cl}$, confidence interval; L-TERPT, transanal pull-through with laparoscopic assistance; OPEN, conventional pull-through procedure via laparotomy; OR, odds ratio; TERPT, transanal pull-through without laparoscopic assistance.

Note: Constipation was significantly more frequent after OPEN surgery compared with L-TERPT/TERPT (OR 3.89 [95\% Cl, 2.69 to 5.62]; $p<0.0001$ ).

with additional problems due to extensive stretching by retractors to gain visualization with subsequent damage to the anal canal. ${ }^{36}$

To date, there has been no randomized controlled study evaluating the long-term outcome of OPEN surgery compared with L-TERPT/TERPT. ${ }^{36,37}$ Therefore, the present review could only focus on retrospective studies with a high variability of follow-up periods and definition of outcome parameters. We focused on long-term outcome in HD patients operated with conventional transabdominal pull-through (OPEN) compared with transanal endorectal pull-through with or without laparoscopy (L-TERPT/TERPT) using four major outcome parameters: constipation, incontinence, enterocolitis and anastomotic stricture.

\section{Constipation}

The incidence of postpull-through constipation in the current literature ranges from 0 to $59 \%{ }^{10,20,38,39}$ Suspected causes include abnormal motility of the pulled-through segment and abnormal function of the internal anal sphincter due to the underlying disease or preceding surgery. ${ }^{36,37,40}$ However, most authors describe an improvement of constipation in late childhood. Our systematic review revealed postoperative constipation rates of up to 59\%. Furthermore, it confirms previous reports on a higher incidence of postoperative constipation after OPEN surgery when compared with LTERPT/TERPT. ${ }^{39,41,42}$ The causes for these findings remain elusive. However, one could speculate that extensive pelvic dissection as it is performed in OPEN surgery may lead to 
Table 2 Frequency of postoperative soiling

\begin{tabular}{|c|c|c|c|c|c|c|}
\hline Group & Author & Year & Surgical technique & Patients, $N$ & Soiling, $N$ & Soiling, $\%$ \\
\hline \multirow[t]{11}{*}{ OPEN } & Yokoi et al & 2009 & Modified Swenson & 10 & 1 & 10 \\
\hline & Aslanabadi et al & 2008 & Swenson & 21 & 2 & 10 \\
\hline & Nah et al & 2012 & Duhamel & 41 & 6 & 15 \\
\hline & Yokoi et al & 2009 & Swenson & 64 & 11 & 17 \\
\hline & Gunnarsdottir & 2010 & Duhamel & 17 & 3 & 18 \\
\hline & Gad El-Hak et al & 2010 & Swenson & 52 & 17 & 33 \\
\hline & Romero et al & 2011 & $\begin{array}{l}\text { Soave, Duhamel, } \\
\text { Swenson, Rehbein }\end{array}$ & 23 & 10 & 43 \\
\hline & Tannuri et al & 2009 & Duhamel & 29 & 12 & 41 \\
\hline & Ishikawa et al & 2008 & Unspecified & 20 & 9 & 45 \\
\hline & Stensrud et al & 2010 & Unspecified & 24 & 14 & 58 \\
\hline & Aworanti et al & 2012 & Soave & 28 & 21 & 75 \\
\hline Total & & & & 329 & 106 & 33 \\
\hline \multirow[t]{3}{*}{ L-TERPT } & Nguyen et al & 2009 & Soave & 157 & 3 & 2 \\
\hline & Tang et al & 2012 & Soave & 182 & 7 & 4 \\
\hline & Yokoi et al & 2009 & Swenson & 15 & 5 & 33 \\
\hline \multirow[t]{10}{*}{ TERPT } & Aslanabadi et al & 2008 & Soave & 21 & 0 & 0 \\
\hline & Dutta & 2010 & Soave & 45 & 2 & 4 \\
\hline & Yang et al & 2012 & Soave & 137 & 6 & 4 \\
\hline & Gunnarsdottir & 2010 & Soave & 11 & 1 & 9 \\
\hline & Kim et al & 2010 & Soave & 192 & 20 & 10 \\
\hline & Sookpotarom and Vejchapipat & 2009 & Swenson & 18 & 4 & 22 \\
\hline & Tannuri et al & 2009 & Soave & 24 & 7 & 29 \\
\hline & Stensrud et al & 2010 & Soave & 28 & 15 & 54 \\
\hline & Aworanti et al & 2012 & Soave & 14 & 10 & 71 \\
\hline & Romero et al & 2011 & Unspecified & 16 & 14 & 88 \\
\hline Total & & & & 860 & 94 & 25 \\
\hline
\end{tabular}

Abbreviations: $\mathrm{Cl}$, confidence interval; L-TERPT, transanal pull-through with laparoscopic assistance; OPEN, conventional pull-through procedure via laparotomy; OR, odds ratio; TERPT, transanal pull-through without laparoscopic assistance.

Note: Soiling/incontinence occurred significantly more frequently after OPEN surgery compared with L-TERPT/TERPT (OR 3.87[95\% CI, 2.83 to 5.31]; $p<0.0001)$.

iatrogenic pelvic-nerve injury compromising rectal motility and subsequently leading to constipation. $33,36,37,43$

\section{Soiling/Incontinence}

Most patients with HD have been reported to suffer from soiling which remains the major cause of psychological and social problems in these patients. ${ }^{40,44}$ Frank incontinence is rare. Besides constipation, fecal soiling/incontinence has therefore been identified as the most relevant long-term complication after any type of surgery for HD. ${ }^{36,40,45-48}$ Three major causes of soiling have been described: abnormal sphincter function, abnormal sensation, and "pseudoincontinence." The latter is caused by either severe constipation with fecal overflow or hypermotility of the pulled-through colon. ${ }^{33,36,37}$ Levitt et al postulate that sphincter function and sensation may be damaged during the primary repair, and that the colonic motility is substantially affected by an operation for HD. ${ }^{36}$ However, it is noteworthy that patients with HD lack rectoanal relaxation reflex not only after but also before surgery. ${ }^{40,49,50}$ Therefore, it remains unclear to what extent surgical dissection of the rectum compromises relevant nerval structures responsible for anal canal sensation, sphincter competence, and colonic motility.

There is an ongoing debate on whether the incidence of soiling/incontinence is associated with the operative technique. $^{40,51-53}$ Some authors suggest that extensive mechanical stretching during L-TERPT/TERPT by retractors can damage the anal canal and might therefore lead to a higher incidence of incontinent HD patients. ${ }^{36}$ However, our data do not reflect these concerns as it shows that soiling/ 
Table 3 Frequency of postoperative enterocolitis

\begin{tabular}{|c|c|c|c|c|c|c|}
\hline Group & Author & Year & Surgical technique & Patients, $N$ & Enterocolitis, $N$ & Enterocolitis, \% \\
\hline \multirow[t]{11}{*}{ OPEN } & Tannuri et al & 2009 & Duhamel & 29 & 1 & 3 \\
\hline & Stensrud et al & 2010 & Unspecified & 24 & 1 & 4 \\
\hline & Giuliani et al & 2011 & Duhamel & 24 & 1 & 4 \\
\hline & Mattioli et al & 2008 & Soave & 21 & 2 & 10 \\
\hline & Romero et al & 2011 & $\begin{array}{l}\text { Soave, Duhamel, } \\
\text { Swenson, Rehbein }\end{array}$ & 29 & 3 & 10 \\
\hline & Gunnarsdottir & 2010 & Duhamel & 17 & 2 & 12 \\
\hline & Nah et al & 2012 & Duhamel & 41 & 5 & 12 \\
\hline & Yokoi et al & 2009 & Modified Swenson & 10 & 2 & 20 \\
\hline & Aslanabadi et al & 2008 & Swenson & 21 & 5 & 24 \\
\hline & Ishikawa et al & 2008 & Unspecified & 20 & 5 & 25 \\
\hline & Yokoi et al & 2009 & Swenson & 64 & 20 & 31 \\
\hline Total & & & & 300 & 47 & 14 \\
\hline \multirow[t]{5}{*}{ L-TERPT } & Giuliani et al & 2011 & Soave & 14 & 0 & 0 \\
\hline & Tang et al & 2012 & Soave & 182 & 14 & 8 \\
\hline & Mattioli et al & 2008 & Soave & 25 & 2 & 8 \\
\hline & Nguyen et al & 2009 & Soave & 157 & 15 & 10 \\
\hline & Yokoi et al & 2009 & Swenson & 15 & 5 & 33 \\
\hline \multirow[t]{9}{*}{ TERPT } & Yang et al & 2012 & Soave & 137 & 10 & 7 \\
\hline & Aslanabadi et al & 2008 & Soave & 21 & 1 & 5 \\
\hline & Romero et al & 2011 & Unspecified & 24 & 2 & 8 \\
\hline & Dutta & 2010 & Soave & 45 & 5 & 11 \\
\hline & Sookpotarom and Vejchapipat & 2009 & Swenson & 27 & 3 & 11 \\
\hline & Gunnarsdottir & 2010 & Soave & 11 & 2 & 18 \\
\hline & Tannuri et al & 2009 & Soave & 35 & 7 & 20 \\
\hline & Stensrud et al & 2010 & Soave & 28 & 7 & 25 \\
\hline & Kim et al & 2010 & Soave & 192 & 65 & 34 \\
\hline Total & & & & 913 & 138 & 14 \\
\hline
\end{tabular}

Abbreviations: $\mathrm{Cl}$, confidence interval; L-TERPT, transanal pull-through with laparoscopic assistance; OPEN, conventional pull-through procedure via laparotomy; OR, odds ratio; TERPT, transanal pull-through without laparoscopic assistance.

Note: There was no significant difference between the rate of enterocolitis after OPEN pull-through and the rate of enterocolitis after L-TERPT/TERPT (OR 1.04 [95\% Cl, 0.73 to 1.50$] ; p=0.8177$ ).

incontinence occurs significantly more often after OPEN compared with L-TERPT/TERPT surgery. The higher incidence of soiling/incontinence in the OPEN surgery group may derive from deep pelvic dissection affecting pelvic nerves and therefore compromising both sphincter function and sensation. ${ }^{33}$ On the other hand, the frequency of constipation was also higher in the OPEN group which could indicate overflow incontinence.

\section{Enterocolitis}

Hirschsprung-associated enterocolitis (HAEC) represents another major postoperative complication and is the most common cause of death in children with HD. ${ }^{33,54}$ The pathogenesis of HAEC is still unknown. ${ }^{39,55}$ Several risk factors for
HAEC have been identified including diagnosis at young age, anastomotic stricture, and malnutrition. ${ }^{39,56,57}$

Some authors report that obstruction at the level of the anus leading to intestinal stasis may play a major role in HAEC pathogenesis. ${ }^{39,58}$ The potential reasons for intestinal stasis include a spastic or long cuff, ${ }^{39,59}$ presuming that a shorter cuff might help to reduce postoperative enterocolitis. ${ }^{39,59}$ However, as HAEC may occur both before and after surgery for $\mathrm{HD},{ }^{60}$ the high incidence of HAEC cannot be explained by partial obstruction alone. ${ }^{39}$

We did not find a significant difference in the incidence of enterocolitis after OPEN surgery compared with L-TERPT/ TERPT. This may indicate that HAEC is rather part of the underlying pathology of HD than a result of a particular 
Table 4 Frequency of postoperative anastomotic stricture

\begin{tabular}{|l|l|l|l|l|l|l|}
\hline Group & Author & Year & Surgical technique & Patients, $N$ & Stricture, $N$ & Stricture, \% \\
\hline OPEN & Tannuri et al & 2009 & Duhamel & 29 & 0 & 0 \\
\cline { 2 - 6 } & Aslanabadi et al & 2008 & Swenson & 21 & 0 & 0 \\
\cline { 2 - 6 } & Giuliani et al & 2011 & Duhamel & 24 & 0 & 0 \\
\cline { 2 - 6 } & Nah et al & 2012 & Duhamel & 41 & 1 & 2 \\
\cline { 2 - 6 } & Mattioli et al & 2008 & Soave & 21 & 1 & 5 \\
\cline { 2 - 6 } & Gad El-Hak et al & 2010 & Swenson & 52 & 5 & 10 \\
\cline { 2 - 6 } & Romero et al & 2011 & Soave, Duhamel, & 29 & 5 & 17 \\
\cline { 2 - 6 } & Stensrud et al & & Swenson, Rehbein & & & \\
\hline L-TERPT & Mattioli et al & 2010 & Unspecified & 24 & 5 & 21 \\
\cline { 2 - 6 } & Tang et al & & & 241 & 17 & 7 \\
\cline { 2 - 6 } & Nguyen et al & 2008 & Soave & 25 & 0 & 0 \\
\cline { 2 - 6 } & Giuliani et al & 2012 & Soave & 182 & 4 & 2 \\
\hline \multirow{7}{*}{ TERPT } & Aslanabadi et al & 2009 & Soave & 157 & 6 & 4 \\
\cline { 2 - 6 } & Yang et al & 2011 & Soave & 14 & 1 & 7 \\
\cline { 2 - 6 } & Dutta & 2008 & Soave & 21 & 0 & 0 \\
\cline { 2 - 6 } & Romero et al & 2012 & Soave & 137 & 2 & 1 \\
\cline { 2 - 6 } & Tannuri et al & 2010 & Soave & 45 & 2 & 4 \\
\cline { 2 - 6 } & Kim et al & 2011 & Unspecified & 24 & 1 & 4 \\
\cline { 2 - 6 } & Gunnarsdottir & 2009 & Soave & 35 & 3 & 9 \\
\cline { 2 - 6 } & Sookpotarom and Vejchapipat & 2010 & Soave & 192 & 17 & 9 \\
\cline { 2 - 6 } & Stensrud et al & 2010 & Soave & 11 & 1 & 9 \\
\hline Total & & Swenson & 27 & 6 & 22 \\
\hline
\end{tabular}

Abbreviations: $\mathrm{Cl}$, confidence interval; L-TERPT, transanal pull-through with laparoscopic assistance; OPEN, conventional pull-through procedure via laparotomy; OR, odds ratio; TERPT, transanal pull-through without laparoscopic assistance.

Note: No significant difference was found comparing occurrence of strictures after OPEN pull-through versus L-TERPT/TERPT (OR 1.16 [95\% Cl, 0.66 to 2.04]; $p=0.5989$ ).

surgical technique. Moreover, the lack of a clear definition of HAEC remains a major problem that could account for the wide range of incidence reported from 5 to $50 \%{ }^{60}$

\section{Anastomotic Stricture}

Multiple risk factors for anastomotic stricture including anastomotic ischemia, anastomotic leakage, and cuff ischemia have been described. ${ }^{39,41,61}$ Various surgical techniques were suggested to prevent stricture formation, such as an oblique coloanal anastomosis reported by Swenson. ${ }^{39,62}$

The studies analyzed in this review showed no significant difference in the incidence of anastomotic stricture after OPEN surgery compared with L-TERPT/TERPT surgery.

\section{Drawbacks/Limitations of the Study}

Although the present review of the recent literature revealed a higher incidence of constipation and soiling/incontinence after OPEN surgery compared with L-TERPT/TERPT, these data need to be carefully interpreted. The following limita- tions of the present analysis and validity of the data on the long-term outcome in the current literature may be discussed:

- There was a lack of uniform definitions of outcome parameters after surgery for HD such as constipation, soiling, incontinence, enterocolitis, and stricture.

- In a very few studies, standardized scores to describe endpoints were used.

- L-TERPT and TERPT were analyzed as one group, which is due to the difficulty to distinguish whether laparoscopy was used for biopsies only or for dissection of the rectum. A comprehensive description of the surgical technique was lacking in numerous reports.

- The OPEN surgery group consisted of several pull-through techniques such as Soave, Swenson, Duhamel, and Rehbein which might have led to a high variability of results.

- The OPEN group was comparable to the L-TERPT/TERPT group in terms of "age at surgery" and "group size" but the follow-up period was significantly longer. As the functional 
results tend to be more favorable with increasing age, the high rate of constipation and soiling in the OPEN group is remarkable.

- Comparative, randomized studies evaluating outcome of OPEN surgery versus L-TERPT/TERPT were not available for this review. Therefore, the validity of the data and level of evidence of the present analysis is limited.

\section{Conclusion}

Functional outcome of different surgical techniques for HD is highly variable. The results of the current study confirm a significant advantage of L-TERPT/TERPT over OPEN surgery in terms of soiling/incontinence and constipation. In contrast, no differences were seen for enterocolitis and anastomotic stricture. Several limitations to this systematic review such as the different quality of studies and small cohort sizes need to be considered when interpreting these data. Moreover, only few authors used standardized scores to assess functional outcome. Hence, prospective, randomized, multicenter trials are urgently needed to overcome this weakness of the available reports in current literature.

\section{Conflict of Interest}

None

\section{References}

1 Swenson O, Bill AH Jr. Resection of rectum and rectosigmoid with preservation of the sphincter for benign spastic lesions producing megacolon; an experimental study. Surgery 1948;24(2):212-220

2 So HB, Schwartz DL, Becker JM, Daum F, Schneider KM. Endorectal "pull-through" without preliminary colostomy in neonates with Hirschsprung's disease. J Pediatr Surg 1980;15(4):470-471

3 Georgeson KE, Fuenfer MM, Hardin WD. Primary laparoscopic pull-through for Hirschsprung's disease in infants and children. J Pediatr Surg 1995;30(7):1017-1021, discussion 1021-1022

4 De la Torre-Mondragón L, Ortega-Salgado JA. Transanal endorectal pull-through for Hirschsprung's disease. J Pediatr Surg 1998;33 (8):1283-1286

5 Albanese CT, Jennings RW, Smith B, Bratton B, Harrison MR. Perineal one-stage pull-through for Hirschsprung's disease. J Pediatr Surg 1999;34(3):377-380

6 Gao Y, Li G, Zhang X, et al. Primary transanal rectosigmoidectomy for Hirschsprung's disease: Preliminary results in the initial 33 cases. J Pediatr Surg 2001;36(12):1816-1819

7 Langer JC, Minkes RK, Mazziotti MV, Skinner MA, Winthrop AL. Transanal one-stage Soave procedure for infants with Hirschsprung's disease. J Pediatr Surg 1999;34(1):148-151, discussion 152

8 Liu DC, Rodriguez J, Hill CB, Loe WA Jr. Transanal mucosectomy in the treatment of Hirschsprung's disease. J Pediatr Surg 2000;35 (2):235-238

9 Huang Y, Zheng S, Xiao X. A follow-up study on postoperative function after a transanal Soave 1-stage endorectal pull-through procedure for Hirschsprung's disease. J Pediatr Surg 2008;43 (9):1691-1695

10 Ishikawa N, Kubota A, Kawahara H, et al. Transanal mucosectomy for endorectal pull-through in Hirschsprung's disease: comparison of abdominal, extraanal and transanal approaches. Pediatr Surg Int 2008;24(10):1127-1129
11 El-Sawaf MI, Drongowski RA, Chamberlain JN, Coran AG, Teitelbaum $\mathrm{DH}$. Are the long-term results of the transanal pull-through equal to those of the transabdominal pull-through? A comparison of the 2 approaches for Hirschsprung disease. J Pediatr Surg 2007;42(1):41-47, discussion 47

12 Elhalaby EA, Hashish A, Elbarbary MM, et al. Transanal one-stage endorectal pull-through for Hirschsprung's disease: a multicenter study. J Pediatr Surg 2004;39(3):345-351, discussion 345-351

13 Obermayr F, Szavay P, Beschorner R, Fuchs J. Outcome of transanal endorectal pull-through in patients with Hirschsprung's disease. Eur J Pediatr Surg 2009;19(4):220-223

14 Tannuri AC, Tannuri U, Romão RL. Transanal endorectal pullthrough in children with Hirschsprung's disease-technical refinements and comparison of results with the Duhamel procedure. J Pediatr Surg 2009;44(4):767-772

15 Aslanabadi S, Ghalehgolab-Behbahan A, Zarrintan S, Jamshidi M, Seyyedhejazi M. Transanal one-stage endorectal pull-through for Hirschsprung's disease: a comparison with the staged procedures. Pediatr Surg Int 2008;24(8):925-929

16 Aworanti OM, Mcdowell DT, Martin IM, Hung J, Quinn F. Comparative review of functional outcomes post surgery for Hirschsprung's disease utilizing the paediatric incontinence and constipation scoring system. Pediatr Surg Int 2012;28(11):10711078

17 Dutta HK. Clinical experience with a new modified transanal endorectal pull-through for Hirschsprung's disease. Pediatr Surg Int 2010;26(7):747-751

18 Gad El-Hak NA, El-Hemaly MM, Negm EH, El-Hanafy EA, Abdel Messeh MH, Abdel Bary HH. Functional outcome after Swenson's operation for Hirshsprung's disease. Saudi J Gastroenterol 2010;16 (1):30-34

19 Giuliani S, Betalli P, Narciso A, et al. Outcome comparison among laparoscopic Duhamel, laparotomic Duhamel, and transanal endorectal pull-through: a single-center, 18-year experience. J Laparoendosc Adv Surg Tech A 2011;21(9):859-863

20 Gunnarsdóttir A, Larsson LT, Arnbjörnsson E. Transanal endorectal vs. Duhamel pull-through for Hirschsprung's disease. Eur J Pediatr Surg 2010;20(4):242-246

$21 \mathrm{Kim}$ AC, Langer JC, Pastor AC, et al. Endorectal pull-through for Hirschsprung's disease-a multicenter, long-term comparison of results: transanal vs transabdominal approach. J Pediatr Surg 2010;45(6):1213-1220

22 Mattioli G, Pini Prato A, Giunta C, et al. Outcome of primary endorectal pull-through for the treatment of classic Hirschsprung disease. J Laparoendosc Adv Surg Tech A 2008;18(6):869-874

23 Nah SA, de Coppi P, Kiely EM, et al. Duhamel pull-through for Hirschsprung disease: a comparison of open and laparoscopic techniques. J Pediatr Surg 2012;47(2):308-312

24 Nguyen TL, Bui DH, Tran AQ Vu TH. Early and late outcomes of primary laparoscopic endorectal colon pull-through leaving a short rectal seromuscular sleeve for Hirschsprung disease. J Pediatr Surg 2009;44(11):2153-2155

25 Romero P, Kroiss M, Chmelnik M, Königs I, Wessel LM, HollandCunz S. Outcome of transanal endorectal vs. transabdominal pullthrough in patients with Hirschsprung's disease. Langenbecks Arch Surg 2011;396(7):1027-1033

26 Sookpotarom P, Vejchapipat P. Primary transanal Swenson pullthrough operation for Hirschsprung's disease. Pediatr Surg Int 2009;25(9):767-773

27 Stensrud KJ, Emblem R, Bjørnland K. Functional outcome after operation for Hirschsprung disease-transanal vs transabdominal approach. J Pediatr Surg 2010;45(8):1640-1644

28 Tang ST, Wang GB, Cao GQ et al. 10 years of experience with laparoscopic-assisted endorectal Soave pull-through procedure for Hirschsprung's disease in China. J Laparoendosc Adv Surg Tech A 2012;22(3):280-284

29 Yang L, Tang ST, Cao GQ, et al. Transanal endorectal pull-through for Hirschsprung's disease using long cuff dissection and short V- 
shaped partially resected cuff anastomosis: early and late outcomes. Pediatr Surg Int 2012;28(5):515-521

30 Yokoi A, Satoh S, Takamizawa S, Muraji T, Tsugawa C, Nishijima E. The preliminary study of modified Swenson procedure in Hirschsprung disease. J Pediatr Surg 2009;44(8):1560-1563

31 De la Torre L, Ortega A. Transanal versus open endorectal pullthrough for Hirschsprung's disease. J Pediatr Surg 2000;35 (11):1630-1632

32 Hadidi A. Transanal endorectal pull-through for Hirschsprung's disease: a comparison with the open technique. Eur J Pediatr Surg 2003;13(3):176-180

33 Langer JC. Laparoscopic and transanal pull-through for Hirschsprung disease. Semin Pediatr Surg 2012;21(4):283-290

34 Langer JC, Durrant AC, de la Torre L, et al. One-stage transanal Soave pullthrough for Hirschsprung disease: a multicenter experience with 141 children. Ann Surg 2003;238(4):569-583, discussion 583-585

35 Travassos DV, Bax NM, Van der Zee DC. Duhamel procedure: a comparative retrospective study between an open and a laparoscopic technique. Surg Endosc 2007;21(12):2163-2165

36 Levitt MA, Martin CA, Olesevich M, Bauer CL, Jackson LE, Peña A. Hirschsprung disease and fecal incontinence: diagnostic and management strategies. J Pediatr Surg 2009;44(1):271-277, discussion 277

37 Levitt M, Peña A. Update on pediatric faecal incontinence. Eur J Pediatr Surg 2009;19(1):1-9

38 Catto-Smith AG, Trajanovska M, Taylor RG. Long-term continence after surgery for Hirschsprung's disease. J Gastroenterol Hepatol 2007;22(12):2273-2282

39 Georgeson KE. Hirschsprung's Disease. In: Holcomb GW III, Murphy JP, eds. Ashcraft's Pediatric Surgery. 5th ed. Oxford: Elsevier LTD; 2010

40 Rintala RJ, Pakarinen MP. Long-term outcomes of Hirschsprung's disease. Semin Pediatr Surg 2012;21(4):336-343

41 Engum SA, Grosfeld JL. Long-term results of treatment of Hirschsprung's disease. Semin Pediatr Surg 2004;13(4):273-285

42 Little DC, Snyder CL. Early and late complications following operative repair of Hirschsprung's disease. In: Holschneider AM, Puri P, eds. Hirschsprung's Disease and Allied Disorders. 3rd ed. New York: Springer; 2003:375-385

43 Finlay IG, Renwick AA. Surgical Management of Constipation. In: Beynon J, Carr ND, eds. Progress in Colorectal Surgery. London: Springer; 2005:267

44 Yanchar NL, Soucy P. Long-term outcome after Hirschsprung's disease: patients' perspectives. J Pediatr Surg 1999;34(7):11521160

45 Bax KN. Duhamel Lecture: the incurability of Hirschsprung's disease. Eur J Pediatr Surg 2006;16(6):380-384

46 Di Lorenzo C, Solzi GF, Flores AF, Schwankovsky L, Hyman PE. Colonic motility after surgery for Hirschsprung's disease. Am J Gastroenterol 2000;95(7):1759-1764
47 Teitelbaum DH, Drongowski RA, Chamberlain JN, Coran AG. Longterm stooling patterns in infants undergoing primary endorectal pull-through for Hirschsprung's disease. J Pediatr Surg 1997;32 (7):1049-1052, discussion 1052-1053

48 Zhang SC, Bai YZ, Wang W, Wang WL. Stooling patterns and colonic motility after transanal one-stage pull-through operation for Hirschsprung's disease in children. J Pediatr Surg 2005;40 (11):1766-1772

49 Heikkinen M, Rintala R, Luukkonen P. Long-term anal sphincter performance after surgery for Hirschsprung's disease. J Pediatr Surg 1997;32(10):1443-1446

50 Jarvi K, Koivusalo A, Rintala RJ, Pakarinen MP. Anorectal manometry with reference to operative rectal biopsy for the diagnosis/ exclusion of Hirschprung's disease in children under 1 year of age. Int J Colorectal Dis 2009;24(4):451-454

51 Bai Y, Chen H, Hao J, Huang Y, Wang W. Long-term outcome and quality of life after the Swenson procedure for Hirschsprung's disease. J Pediatr Surg 2002;37(4):639-642

52 Reding R, de Ville de Goyet J, Gosseye S, et al. Hirschsprung's disease: a 20-year experience. J Pediatr Surg 1997;32(8):1221-1225

53 Shankar KR, Losty PD, Lamont GL, et al. Transanal endorectal coloanal surgery for Hirschsprung's disease: experience in two centers. J Pediatr Surg 2000;35(8):1209-1213

54 Lacher M, Fitze G, Helmbrecht J, et al. Hirschsprung-associated enterocolitis develops independently of NOD2 variants. J Pediatr Surg 2010;45(9):1826-1831

55 Coran AG, Teitelbaum DH. Recent advances in the management of Hirschsprung's disease. Am J Surg 2000;180(5):382-387

56 Haricharan RN, Seo JM, Kelly DR, et al. Older age at diagnosis of Hirschsprung disease decreases risk of postoperative enterocolitis, but resection of additional ganglionated bowel does not. J Pediatr Surg 2008;43(6):1115-1123

57 Teitelbaum DH, Cilley RE, Sherman NJ, et al. A decade of experience with the primary pull-through for hirschsprung disease in the newborn period: a multicenter analysis of outcomes. Ann Surg 2000;232(3):372-380

58 Hackam DJ, Filler RM, Pearl RH. Enterocolitis after the surgical treatment of Hirschsprung's disease: risk factors and financial impact. J Pediatr Surg 1998;33(6):830-833

59 Nasr A, Langer JC. Evolution of the technique in the transanal pullthrough for Hirschsprung's disease: effect on outcome. J Pediatr Surg 2007;42(1):36-39, discussion 39-40

60 Pastor AC, Osman F, Teitelbaum DH, Caty MG, Langer JC. Development of a standardized definition for Hirschsprung's-associated enterocolitis: a Delphi analysis. J Pediatr Surg 2009;44(1):251-256

61 Teitelbaum DH, Coran AG. Long-term results and quality of life after treatment of Hirschsprung's disease and allied disorders. In: Holschneider AM, Puri P, eds. Hirschsprung's Disease and Allied Disorders. 3rd ed. New York: Springer; 2008:389-397

62 Swenson O. How the cause and cure of Hirschsprung's disease were discovered. J Pediatr Surg 1999;34(10):1580-1581 